\title{
Adult Jejuno-Jejunal Intussusceptions due to Gastrointestinal Stromal Tumor
}

\begin{abstract}
Intussusception is telescoping of proximal segment of the intestine within the lumen of adjacent segment of intestine. In children, most of the intussusception is idiopathic, whereas in adults, it is always associated with pathological lead point. In adults, jejuno-jejunal intussusception is very rare compared to children. Preoperative diagnosis is difficult in most of the cases, so adequate negative margin is mandatory when a gastrointestinal stromal tumor (GIST) is suspected as the cause of jejuno-jejunal intussusception. This case is reported because jejunal intussusception is one of the rare presentations of GIST.
\end{abstract}

Keywords: Anastomosis, gastrointestinal stromal tumor, jejuno jejunal intussusception, resection

\section{Introduction}

Intussusception is the telescoping of proximal segment of the intestine within the lumen of the adjacent segment of intestine. ${ }^{[1]}$ The highest incidence of intussusception is between 4 and 10 months of age. The incidence of intussusception is higher in children compared to adults. The types of intussusception include ileocolic (77\%), ileo-ileo-colic (12\%), ileoileal (5\%), colocolic (2\%), ileocecal, jejuno-jejunal, and retrograde intussusception. ${ }^{[2]}$ In adults, colocolic intussusception is the most common, whereas in children, ileocolic intussusception is common. Jejuno-jejunal intussusception is a rare site for adult intussusception.

\section{Case Report}

A 45-year-old male presented with complaints of abdominal pain for 4 days associated with a history of nausea and vomiting for 3 days. On examination, the patient was conscious, oriented, and febrile. Pulse rate was $110 / \mathrm{min}$, and blood pressure was $80 / 60 \mathrm{mmHg}$. On abdominal examination, there was distension with guarding and rigidity. On auscultation, bowel sounds were absent.

Investigation showed anemia with leukocytosis. Renal function tests and liver

This is an open access journal, and articles are distributed under the terms of the Creative Commons Attribution-NonCommercial-ShareAlike 4.0 License, which allows others to remix, tweak, and build upon the work non-commercially, as long as appropriate credit is given and the new creations are licensed under the identical terms.

For reprints contact: WKHLRPMedknow_reprints@wolterskluwer.com function tests were altered. Computed tomography of the abdomen showed dilated small bowel loops with free fluid. Preoperative diagnosis made as small intestine obstruction and planned for laparotomy. Intraoperative findings were small bowel obstruction due to jejuno-jejunal intussusception with jejunal gangrene [Figures 1 and 2]. Primary resection and anastomosis were performed due to the gangrenous bowel. Cut opened specimen of the jejunum showed an intraluminal mass lesion acting as a leading point for intussusception [Figure 3]. Postoperative histopathological examination showed proliferation of bland spindle cells with pale-to-eosinophilic fibrillar cytoplasm [Figure 4]. Tumor showed strong positive reaction for $\mathrm{CD} 117$ and $\mathrm{CD} 34$ with negative resected margin [Figures 5 and 6]. The above-mentioned findings confirmed the diagnosis of gastrointestinal stromal tumor (GIST). Postoperative recovery was uneventful.

\section{Discussion}

Intestinal obstruction due to intussusceptions is more common in children than in adults. In adults, intestinal obstruction due to intussusception is $<1 \%$. The intussusception in children is mostly idiopathic, and in adults, it is usually associated with pathological lead point. ${ }^{[3]}$

The clinical features of intussusception are nonspecific in adults compared to children.

How to cite this article: Pandiaraja J. Adult jejunojejunal intussusceptions due to gastrointestinal stromal tumor. Indian J Med Paediatr Oncol 2020;41:602-4.

\section{Jayabal Pandiaraja}

Department of General Surgery, Care Hospital, Chennai,

Tamil Nadu, India

Submitted: $15-$ Sep-2018

Revised: $20-$ Oct-2019

Accepted: 21-Oct-2019

Published: 29-Aug-2020

Address for correspondence: Dr. Jayabal Pandiaraja, Care Hospital, Villivakkam, Chennai - 603 203,

Tamil Nadu, India.

E-mail:drpandiaraja@gmail. com

Access this article online Website: www.ijmpo.org

DOI: 10.4103/ijmpo.ijmpo_203_18 Quick Response Code:
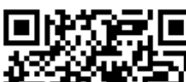


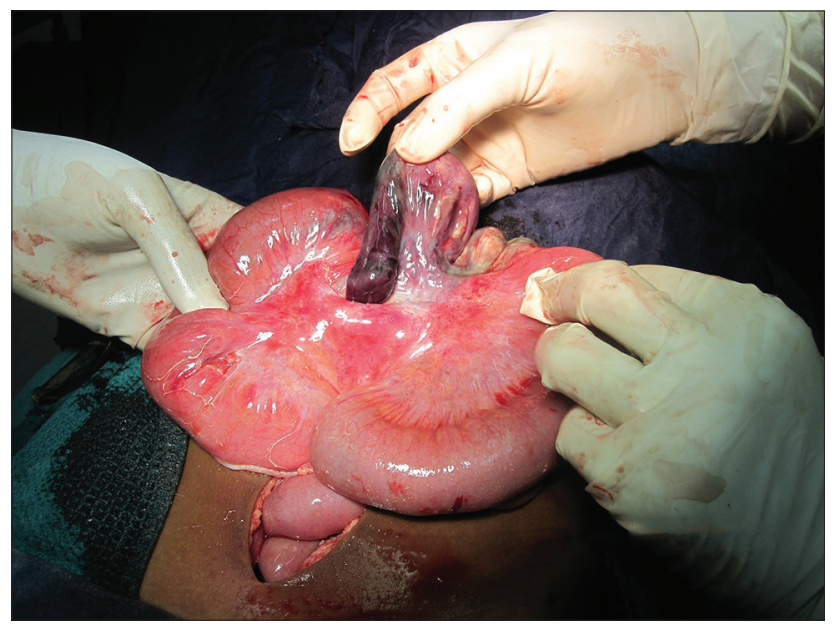

Figure 1: Intraoperative picture of jejuno-jejunal intussusception

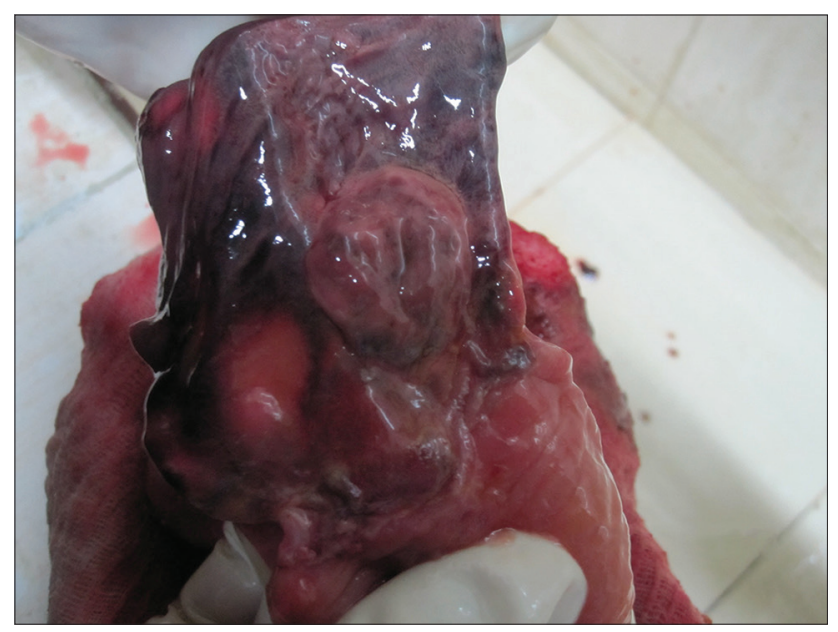

Figure 3: Cut opened specimen of jejunum showing an intraluminal mass lesion as a leading point

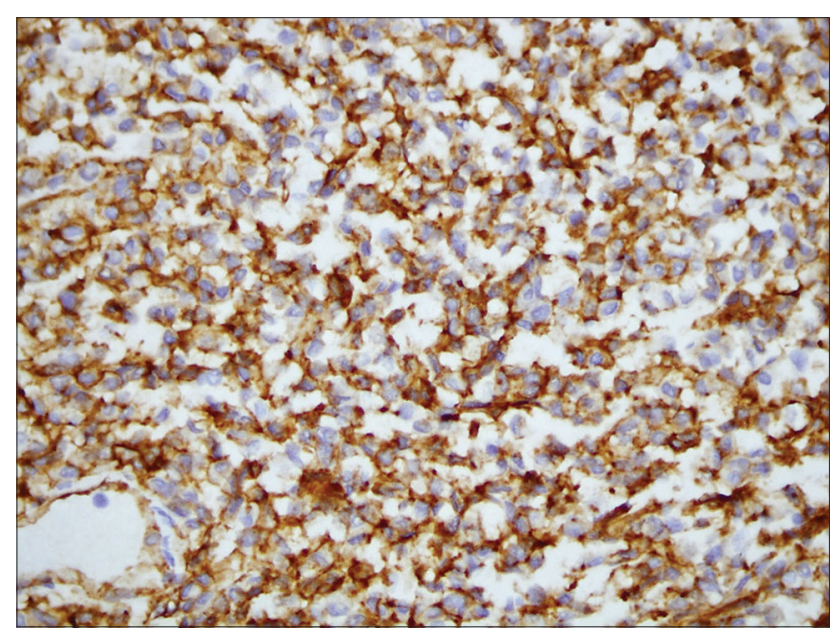

Figure 5: Tumor showing strong positive reaction for CD34

Most adult intussusceptions present with features of intestinal obstruction. ${ }^{[4]}$ In most of the literature described, abdominal pain is the most common symptom followed by nausea and vomiting. ${ }^{[5]}$ Plain abdominal X-rays, barium

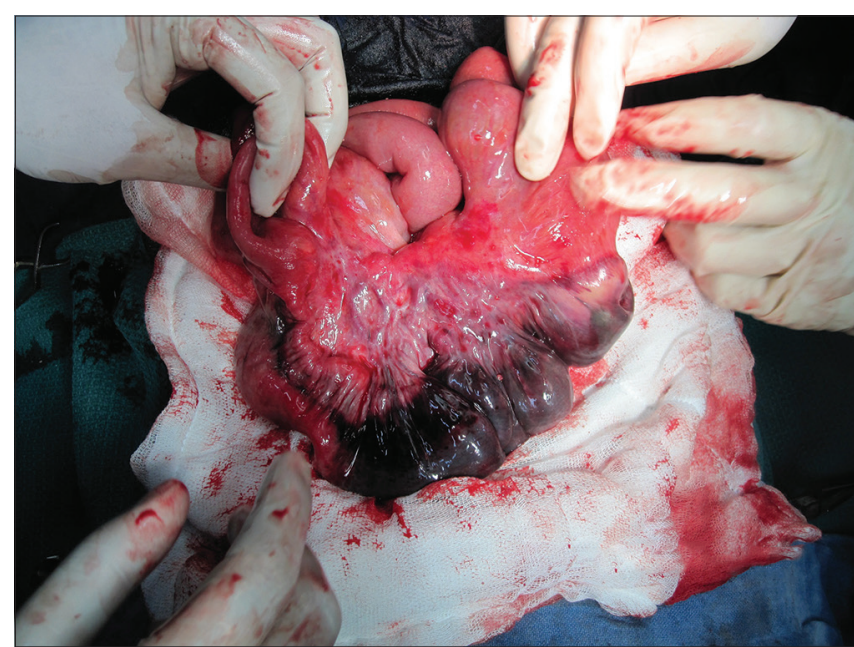

Figure 2: Jejuno-jejunal intussusception with loop of jejunal gangrene

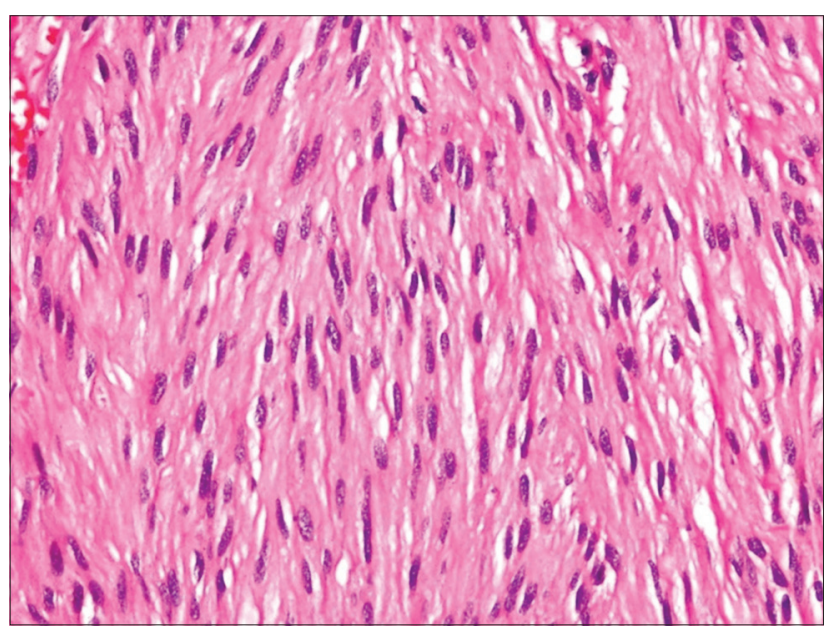

Figure 4: Postoperative histopathology examination showing proliferation of bland spindle cells with pale-to-eosinophilic fibrillar cytoplasm with features of gastrointestinal stromal tumor

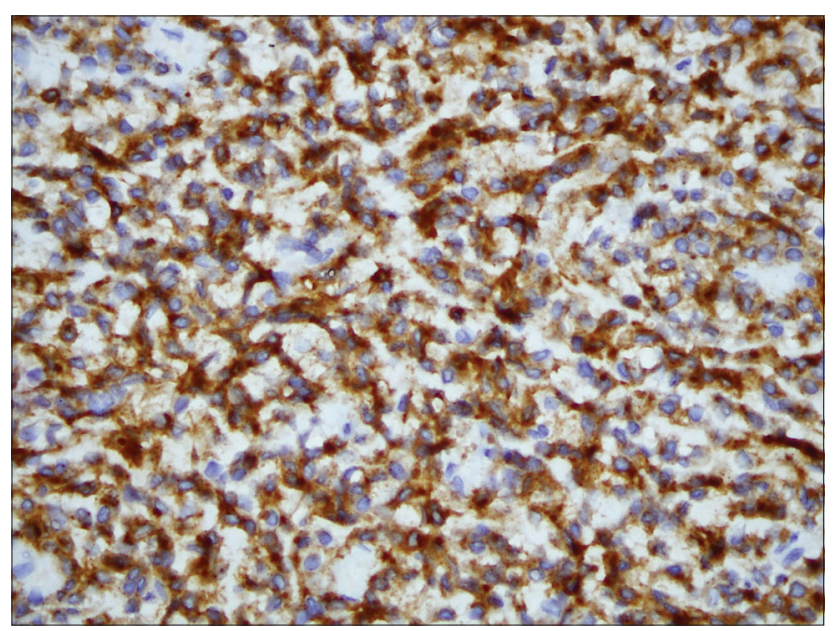

Figure 6: Tumor showing strong positive reaction for CD117

upper gastrointestinal series, barium enema, ultrasound, and abdominal computed tomography (CT) scan are used for the diagnosis of intussusception. Diagnostic laparoscopy added 
a milestone for diagnosis of intussusception. ${ }^{[6]}$ Similar to our case report, most of the jejuno-jejunal intussusception causes are identified by postoperative histopathological examination.

The other causes of jejuno-jejunal intussusception reported in the literature include lymphoma, postgastrojejunostomy, Roux en-y gastric bypass, postoperative jejuno-jejunal anastomosis, jejunal polyp in Peutz-Jeghers syndrome, metastatic melanoma, lipoma, fibroma, adenocarcinoma, GIST, and ectopic pancreatic tissue. ${ }^{[1]}$

GIST is a relatively rare mesenchymal tumor that originates from interstitial cells of Cajal. GIST constitutes $1 \%$ of primary gastrointestinal malignancies. Only few cases reported GISTs as a leading point of adult intussusception. ${ }^{[7]}$

The incidence of GIST varies from $40 \%$ to $60 \%$ in stomach, $25 \%$ to $30 \%$ in jejunum, $5 \%$ to $15 \%$ in colorectum, $5 \%$ in duodenum, and $<1 \%$ in esophagus. ${ }^{[8-10]}$ Contrast CT is the investigation of choice for evaluation of primary tumor and accurate staging, but in intussusception due to GIST, diagnosis is commonly made in the postoperative specimen rather than preoperative imaging. Segmental resection with negative margin is the treatment of choice for resectable tumor, where imatinib is preferred when the tumor is borderline resectable or unresectable tumor. ${ }^{[11]}$ The management of GIST due to intussusception is slightly different from conventional management of GIST. In most of the cases, primary resection and anastomosis are done for the management of intussusception and management planned according to postoperative histopathology report.

\section{Conclusion}

Intussusception is a rare cause of intestinal obstruction in adults. GIST as a cause of jejuno-jejunal intussusception is rarely reported. Management includes primary resection with negative margin. Preoperative diagnosis is difficult in most of the cases, so adequate negative margin is mandatory when GIST is suspected as a cause of jejuno-jejunal intussusception.

\section{Declaration of patient consent}

The authors certify that they have obtained all appropriate patient consent forms. In the form the patient(s) has/have given his/her/their consent for his/her/their images and other clinical information to be reported in the journal. The patients understand that their names and initials will not be published and due efforts will be made to conceal their identity, but anonymity cannot be guaranteed.

\section{Financial support and sponsorship}

Nil.

\section{Conflicts of interest}

There are no conflicts of interest.

\section{References}

1. Kang SH, Kim SW, Moon HS, Sung JK, Jeong HY, Kim JS, et al. Inflammatory fibroid polyp in the jejunum causing small bowel intussusception. Ann Coloproctol 2015;31:106-9.

2. Loukas M, Pellerin M, Kimball Z, de la Garza-Jordan J, Tubbs RS, Jordan R, et al. Intussusception: An anatomical perspective with review of the literature. Clin Anat 2011;24:552-61.

3. Analay H, Gümüş N, Erkiliç A, Biçer H. A rare cause of acute abdomen in an adult burn patient: Jejuno-jejunal intussusception. J Burn Care Res 2015;36:e229.

4. Kimura N, Hight M, Liang J, Willy R, Liang K, Camp J, et al. Adult intussusception secondary to inflammatory fibroid polyp. West J Emerg Med 2015;16:581-2.

5. Yoldas T, Karaca AC, Ozturk S, Unver M, Calıskan C, Korkut MA. A rare cause of colonic obstruction "colonic intussusception": Report of two cases. Case Rep Surg 2015;2015:465374.

6. Katz KN, Skole K, Fede JM. An unusual case of obstruction due to colonic intussusception in a scleroderma patient. ACG Case Rep J 2014;2:30-2.

7. Zakaria AH, Daradkeh S. Jejunojejunal intussusception induced by a gastrointestinal stromal tumor. Case Rep Surg 2012;2012:173680.

8. Ud Din N, Ahmad Z, Arshad H, Idrees R, Kayani N. Gastrointestinal stromal tumors: A clinicopathologic and risk stratification study of 255 cases from Pakistan and review of literature. Asian Pac J Cancer Prev 2015;16:4873-80.

9. Gunaydin M, Biçakci U, Bozkurter AT, Elli M, Tander B, Bariş S, et al. Gastrointestinal stromal tumor: A very rare cause of jejunoileal intussusception in a 6-year-old girl. J Pediatr Surg 2012;47:E15-8.

10. Li J, Zhang H, Lu Y, Chen Z, Su K. Presence of PDGFRA and DOG1 mutations in gastrointestinal stromal tumors among Chinese population. Int J Clin Exp Pathol 2015;8:5721-6.

11. Yoo C, Ryu MH, Jo J, Park I, Ryoo BY, Kang YK, et al. Efficacy of imatinib in patients with platelet-derived growth factor receptor alpha-mutated gastrointestinal stromal tumors. Cancer Res Treat 2016;48:546-52. 